\title{
CONSIDERAÇõES SOBRE O ENSINO DE CAMPO NA ENFERMAGEM
}

\author{
Amália C. de Carvalho
}

Apesar da impressão que o título possa dar, o presente trabalho não tem nenhuma pretensão de abordar o assunto sob todos os seus aspectos. Seu objetivo principal é focalizar o ensino de campo como instrumento eficiente na modificação de hábitos, na criação e no desenvolvimento de atitudes adequadas em relação ao objeto da assistência de enfermagem o doente-pessoa, o ser humano enfermo.

0 ensino de campo é elemento indispensável do sistema de formação de enfermeiras. Consiste em toda a instrução dada a estudantes de enfermagem durante o período de prática nas instituições de saúde, hospitalares ou para-hospitalares. Inclui aquisição de conhecimentos, aquisição e desenvolvimento de habilidades mentais e motoras, modificação de hábitos e atitudes e criação de novos hábitos e de novas atitudes.

Caracteriza-se por englobar todos os tipos de aprendizagem, desde o determinado pela repetição de procedimentos ou técnicas, a fim de aperfeiçoar a qualidade e o tempo de execução dos cuidados de enfermagem, a simples observação do doente, comunicação com ele ou leitura da evolução clínica da moléstia que apresenta, até o conhecimento proporcionado pela observação da assistência prestada por profissionais mais habilitados e experientes. E levado a efeito sob a orientação de uma docente da escola ou da própria enfermeira do campo.

As estudantes em estágio sofrem um processo de interação com o ambiente físico e psicológico do campo. O inter-relacionamento com todo o seu pessoal, que inclui os integrantes das diversas categorias de profissionais da saúde que nele trabalham, pessoal administrativo, de serviços técnicos, e os próprios pacientes, exerce gran-

(*) Docente da Escola de Enfermagem da Universidade de São Paulo. 
de influência na formação da estudante, que poderá aprender através dos exemplos, bons ou maus.

Para essa razão a escolha do campo de prática deve merecer atenção cuidadosa por parte do corpo docente das escolas. Se, por um lado, qualquer hospital pode oferecer oportunidades para a prática de estudantes de medicina e de enfermagem, sob o aspecto da assistência às necessidades biológicas e de saúde dos doentes, por outro lado nem todos podem servir de exemplo perfeito no que se relaciona com o respeito aos direitos e à dignidade do paciente como pessoa.

Nargaret Shetland (1), ao abordar o tema sobre a responsabilidade das escolas no preparo das enfermeiras para o exercício ético, moral e humanístico da enfermagem, tece considerações sobre o mais importante dos propósitos de uma instituição educacional o de colocar todos os conhecimentos existentes a serviço do homem, para aperfeiçoá-lo. Ao focalizar a possibilidade que o pessoal da área da saúde tem de melhorar as condições sanitárias da população, lamenta a desumanidade que caracteriza alguns serviços de saúde, onde existe a tendencia de despersonalizar os pacientes ou clientes, de roubar-lhes a individualidade.

Repetindo críticas anteriormente feitas a certos hospitais norte americanos, acusados de terem uma administração "visando a conveniência dos médicos, das enfermeiras e demais funcionários, deixanclo por último as necessidades dos pacientes" (2), a autora afirma que a preocupação em elaborar rotinas para facilitar o trabalho dos funcionários e produzir maior rendimento em menor período de tempo, leva aqueles que tem como missão servir o próximo a se preocuparem mais com o próprio trabalho do que com as necessidades individuais e os direitos das pessoas a quem devem servir.

Essa descrição poderia servir para retratar muitas das nossas instituições de saúde e muitos dos profissionais que nelas trabalham. Não são raras as ocasiões em que o doente deixa de ter direitos como todo o ser humano tão logo é internado num hospital, passando a sofrer imposições, cerceamento da liberdade de locomoção e até interferencias, inclusive em sua vida privada, em nome do bom andamento dos trabalhos, em obediencia aos regulamentos e rotinas da instituição.

O currículo de enfermagem, desde há muito (para sermos precisas, desde a Lei $n .^{\circ} \quad \mathbf{7 7 5} / 49$ regulamentada pelo Decreto $n .^{\circ}$ 27.426/49), inclui obrigatoriamente disciplinas das ciências do comportamento com o objetivo de of erecer aos estudantes os conhecimentos indispensáveis à compreensão da própria personalidade, e para a comprecnsão e aceitação das ações e reações dos indivíduos 
frente aos desafios do cotidiano. Através do estudo das ciências biológicas, de psicologia, antropologia, sociologia e disciplinas afins, tenta-se fazer ver aos alunos a verdadeira dimensão da pessoa humana, com suas virtudes e defeitos, mas com direitos inalienáveis, dentre os quais o de ser tratado com compreensão e humanidade. Os direitos dos doentes são enfatizados, principalmente no que se refere a assistência médica e de enfermagem, e ao respeito à sua dignidade pessoal.

As atitudes que rrao demonstrar esses conhecimentos teóricos, adquiridos em salas de aula, devem ser criadas ou desenvolvidas na prática da enfermagem, durante o ensino de campo, para que as ações não desmintam as intenções. Nem sempre, porém, o campo de estágio favorece esse aprendizado; por isso, o planejamento dos programas de ensino deve prever a anulação dos efeitos das más práticas e dos maus exemplos, bem como programar a criação de situações em que os estudantes possam apreciar e apresentar comportamentos que traduzam compreensão, simpatia e dedicação pelos seus enfermos, e de respeito à sua dignidade pessoal.

A imposição de tratamento e cuidados de enfermagem sempre foi condenada, justamente por que os pacientes têm o direito e a liberdade de recusar, inclusive, as prescrições médicas. Nossa preocupação coincide com a de James Smith (3) quando pergunta se o cuidado integral que ensinamos aos nossos alunos como constituindo o foco central de toda a assistência de enfermagem é, verdadeiramente, o que os pacientes de nós esperam. Ainda mais que, para prestar esse cuidado integral que inclui os aspectos psicológicos, sociais e religiosos o estudante, modernamente, é orientado no sentido de proceder a uma verdadeira devassa na vida daqueles a quem devem servir e ajudar. Exemplos típicos são alguns formulários e históricos de enfermagem que devem ser preenchidos antes da elaboração dos planos de cuidados individualizados.

Não desejamos entrar no mérito do assunto - se é ou não oportuno esse ensinamento desde o primeiro ou segundo ano do curso. A assistência global às necessidades do paciente é obrigação a que nenhuma enfermeira poderá se eximir. Para ser capaz de prestá-la é que recebe ensinamentos teóricos na escola, aliados a prática orientada nos campos de estágio. Queremos apenas levantar o problema sob o ponto-de-vista do desenvolvimento de atitudes de respeito ao paciente.

Será do seu agrado submeter-se a tantos interrogatórios? Não poderá esquivar-se da anamnese do médico e, muitas vezes, de um ou muitos estudantes de medicina; terá que aceitar também 
que enfermeiras e estudantes de enfermagem o obriguem a tão fastidioso processo? Compreenderá; verdadeiramente, a intenção desses interrogatórios? Saberá em que consiste, e fará mesmo questão de receber o cuidado integral, se isso depender de ter de abdicar da intimidade de sua vida particular? Será que é isso o que realmente espera do pessoal de enfermagem?

E nós docentes, no desejo de ensinar mais e melhor, estaremos desenvolvendo boas atitudes em nossos alunos, ao exigir que submetam os doentes a perguntas por vezes embaraçosas, principalmente quando violam șa vida íntima e privada? Qual o sentido e o valor da intromissão, por exemplo, nos segredos da vida sexual do paciente? Não seria melhor, mais aproveitável e menos traumatizante para pacientes e estudantes, desenvolver nestes o espírito de observação e a facilidade na comunicação casual, para que possam inteirar-se los fatos essenciais ao planejamento de uma boa assistência, sem perturbar a paz, o sossego, a liberdade, o conforto físico t psíquico, e a intimidade do objeto de sua assistência? Daquele de quem se afirma que tem todos os direitos e é a pessoa mais importante do hospital? Não será mesmo possível aprender a prestar assistência integral respeitando a dignidade dos pacientes?

Ao tecer considerações sobre o "papel de doente" que o indivíduo tem que assumir quando é internado num hospital, ocasião em que se vê privado de direitos e privilégios, dos símbolos do seu "status" social, de inclependência de julgamento e de ação, Esther L. Brown (4) sumariza as expectativas do paciente hospitalizado como sendo: espera de alívio para os seus males, tratamento para a moléstia, reconhecimento de seu valor como pessoa, interesse, simpatia, compreensão por parte do pessoal envolvido em sua assistência, e apoio durante todo o período de internação.

E, voltando à opinião de James Smith, este autor, à pergunta sobre o que é específico na enfermagem, responde com a sugestão de Njhely: auxílio e apoio ao paciente durante toda a sua experiência de individuo enfermo. Significa estar perto, amparar, oferecer compreensão, ouvir, acompanhar nas dificuldades, ensinar, encorajar, aliviar sofrimentos, suprir deficiências determinadas pela doença, oferecer apoio moral; respeitando sempre seus direitos de homem.

O tema deste trabalho é importante, merece estudo e reflexão. Teremos atingido nossos objetivos se suscitar as discussões que esperamos que provoque. 
REVISTA BRASILEIRA DE ENFERMAGEM

\section{REFERENCIA BIBLIOGRÁFICA}

1.- SHETLAND, Margaret L. The responsibility of the Professional School for preparing nurses for ethical, moral, and humanistic practice. Nursing Forum, 8 (1) : 17-27, 1969.

2 - BERG, Roland H. A Report on Hospitals. Look, 23 (3) : 15-19, Fev. 3, 1959 .

3 -. SMITH James P. Teaching care: the perennial dilemma. Nursing Mirros, 133 (17) : 11-14, out. 22, 1971.

1 - BROWN, Esther L. Newer Dimensions of Patient Care I. New York, Russel Sage Foundation, 1961. 